\title{
AN EXPERIENCE IN CULTURAL HERITAGE DOCUMENTATION IN IRAN USING A LOW-COST TECHNIQUE
}

\author{
F. Hassani ${ }^{\mathrm{a}, *}$, M. Rafiee
}

${ }^{a}$ MA. Graduated in Architectural and Urban Restoration, Tehran, Iran - hassanifereshteh@gmail.com

${ }^{\mathrm{b}}$ MSc. Student of Photogrammetry, Dept. of Surveying, University of Tehran, Tehran, Iran - meysam.rafiei@ut.ac.ir

\begin{abstract}
KEY WORDS: Documentation, Kharraqan Tower, Close Range Photogrammetry, Digital Camera, Calibration, PhotoModeler
\end{abstract}
\begin{abstract}
:
Today, the need for preservation of cultural heritage as an important, irreplaceable resource for human is well recognized. In this regard, prior to any conservational measure, detailed documentation and recording of these precious resources should be performed; since this way, not only preservation requirements of the object will be identified, but also the existing condition will be recorded for future generations. Accordingly, since Iran is known as an ancient land possesses valuable historic resources, and due the numerousness of Iran's monuments and the high possibility of occurring natural disasters which are counted as significant threats for the monuments, the necessity of fast and appropriate documentation in this country will be clarified. This paper is in fact a part of the project entitled "Study of the application of digital technologies in recording and rehabilitation of historic buildings" in Iran. Here, the surveying process of aforesaid project's case study which is one of the two Kharraqan Tomb Towers placed in Qazvin province of Iran, using close range photogrammetry and low cost equipment will be demonstrated.
\end{abstract}

\section{INTRODUCTION}

Conservation of historic buildings is of a great importance, due to their high historical and cultural values. But these precious resources are endangered not only because of deterioration over time, but also by many other factors, such as natural disasters, vandalism, wars, etc. which emphasizes on their need for specific cares. However, it is not possible to care for cultural heritage unless we do the first step of conservation process, which is acquiring enough knowledge about the existing condition of it; and it is not possible to gain knowledge of cultural heritage unless a precise documentation is performed. This clarifies the importance of documentation of cultural heritage. But architectural heritage should be in priority of documentation; whereas other elements of our cultural heritage may be protected by putting them in a museum, architectural monuments are widely used and endangered by long term influences of the environment (Droj, 2010).

According to this, and since Iran is a country with great antiquity and numerous valuable cultural heritage inherited from our ancestors in different eras; a research entitled "Study of the application of digital technologies in recording and rehabilitation of historic buildings" was performed in 20122013, which this paper is a part of aforesaid project. After reviewing different techniques of documentation of cultural heritage, in view of this fact that the project was not financially supported, the attempt was put on applying a low-cost technique to document the case study of the project "Eastern Kharraqan Tomb Tower". Finally the decision was utilizing of photogrammetric techniques with the help of a non-metric digital camera.

The need for documentation of historic buildings is greatly admitted by many experts in numerous literatures. In this regard, the most important references can be CIPA's published papers. Besides, there is a variety of papers which have studied different documentation methods. In this regard, photogrammetric techniques have been well reviewed in all aspects by many researchers (e.g. Ogleby \& Rivett, 1985; Karara, 1989; Atkinson, 1996; Patias and Peipe, 2000; Mills et al., 2000; Patias, 2001, Hanke \& Grussenmeyer, 2002; Patias, 2006; etc.). In addition, There are some researches about using non-metric sensors for example, off-the-self digital cameras, (e.g. Patias et al., 1998; Sechidis et al., 1999; Martins Gomes et al., 1999; Peipe and Stefiani 2003; Shashi and Jain, 2007; etc.)

\section{INTRODUCTION TO THE CASE STUDY}

The two Kharraqan Tomb Towers are located in $1 \mathrm{~km}$ west of the village of Hisar-e Valiasr, $33 \mathrm{~km}$ west of Ab-e Garm town, Qazwin-Hamedan Road in Qazwin Province in Iran.

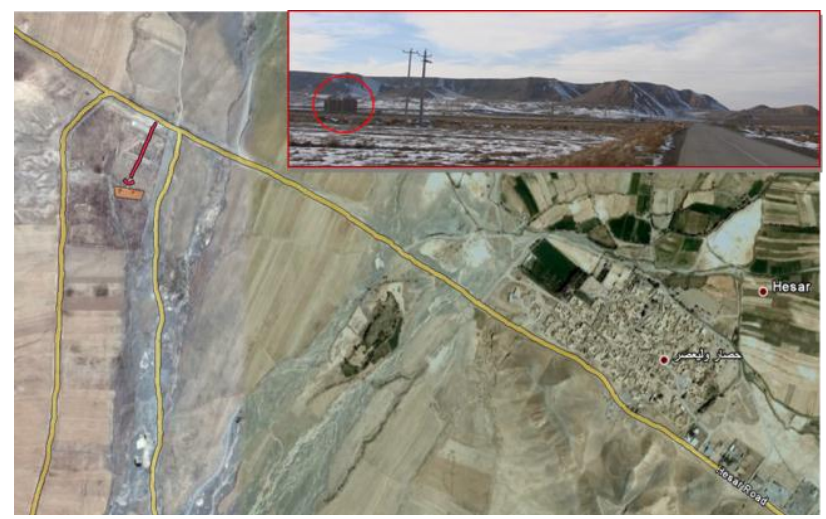

Figure 1. The location of Kharraqan Tomb Towers near Hisar-e Valiasr in Qazvin, as it is obvious they are located in a flat plain

These two towers are particularly notable for their vivid external decoration, which classes them amongst the finest decorated brick monuments found in Iran (Briseghella \& Kalhor, 2007).

\footnotetext{
* Corresponding author.
} 

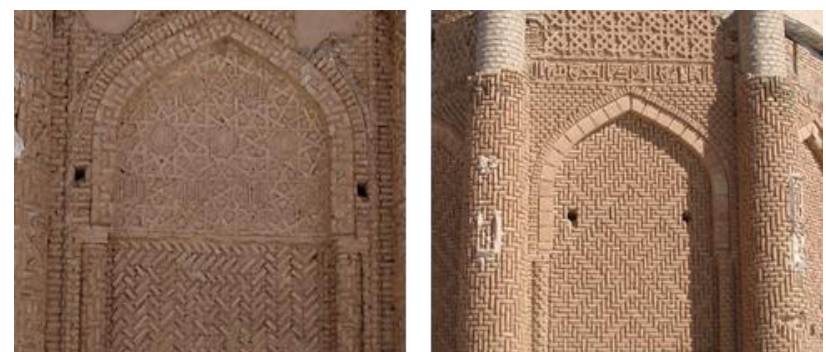

Figure 2. Brick work of the Eastern Kharraqan Tomb Tower, each side has its own unique decoration

They belong to Seljuk period, and their construction dates back to the $11^{\text {th }}$ century. The eastern tomb (the right one in figure 2) is the older one and dates back to the 1067- $68 \mathrm{AC}$; while the western tomb (the left one in figure 2) was constructed 26 years later in $1093 \mathrm{AC}$. It seems that these two mausoleum towers are of the oldest double-domed buildings in Iran. Although these towers are similar to each other, they are significantly different in some cases (exp. In ornamental brick-work, their heights, etc.).

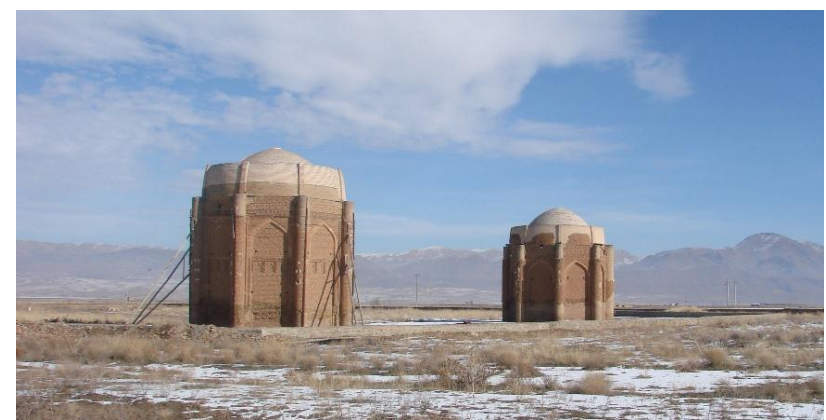

Figure 3. Southern view of Kharraqan Tomb Towers

These two monuments are situated in an earthquake prone region. In fact they have experienced several earthquakes and were considerably damaged in 2002 Avaj Earthquake. Besides, since they are constructed in a flat plain, are endangered by season-rivers and flood so that the moisture accumulation is easily recognizable up to $3 \mathrm{~m}$ of their height. This point clarifies that how these two monuments are in need of further attention and verifies that how much the continuous documentation is important to record the changes every second occur in these buildings.

In this paper, the eastern tomb tower (older one) is considered. This monument has an octagonal plan with eight pillars and two staircases in two of its rounded pillars leading to the space between the two domes. This tower was damaged seriously in Avaj Earthquake, so that its domed cover was almost completely collapsed, and major cracks appeared in the body of the tower. This point clarifies the need for documentation of the tower so that all the changes during time should be recorded in order to protect it against more damages.

\section{SELECTION OF THE SURVEYING TECHNIQUE ACCORDING TO THE EFFECTIVE FACTORS}

Before any work is done, it is essential to select the appropriate tool for documentation. The choice or integration of different tools depends on required accuracy, object dimensions, location constraints, system's portability and usability, surface characteristics, working team experience, project's budget, final goal, etc. (Remondino \& Rizzi, 2009).
In this regard, the most drastic factors in choosing the documentation technique of Kharraqan Tower were the limited budget, the location of the building, which was placed in an almost remote region, and the limitation of time for field working. Therefore, the least possible dependency to expensive complex equipment with limitation in accessibility was the considered factor in selecting the documentation method.

According to what was mentioned above, different methods were studied to choose one that fits better with project facilities. First, since the building has curved surfaces; hand measuring could not be the right selection, as it cannot reach high accuracy. Besides, this technique needs more time to perform field working and reach the result. Other techniques such as surveying with the help of total station or laser scanner were expensive to apply according to the project's budget; and in case of using total station, the fieldwork would be time consuming. Besides, considering the architectural features of Kharraqan Tower, as it possesses valuable ornamental brick work, a technique should be applied to record precisely all the data of surface texturing. This point could not be achieved by any of the mentioned methods. Accordingly, image-based techniques, which can record textural information of the surface, were recognized as the proper methods. In addition, image-based methods can give us a three dimensional model of the object using images taken even by an amateur digital camera. This reduces the amount of costs needed for documentation process.

Finally, considering all the above factors, close range digital photogrammetry was selected to make the project, since it still remains the most complete, economical, portable, flexible and widely used approach in architectural applications, as pointed out by Remondino and El-Hakim (2006) (Armesto et al., 2008). Next step -after choosing the documentation technique- was the selection of appropriate software to process images and meet the project's needs. Therefore, regarding the problems of accessibility of software due to the boycotts Iran has faced, a software should be selected which not only meets the project's requirements, but also there had been no problem for accessing it. So with respect to this problem and with the aim of finding an easier, faster, and cheaper way, PhotoModeler was selected to perform the project. The Canadian PhotoModeler Software Package developed by Eos Systems is well known as a low cost 3D-measurement tool for architectural and archeological applications (Hanke \& Grussenmeyer, 2002). This windowsbased software enables the user to create 3D model of the object and provides the possibility for measuring and exporting dimensions.

In fact, Compared to the conventional photogrammetric procedures, PhotoModeler allows even greater reduction of time and costs for the production of models, since it does not require positioning and measuring of targets and stereoscopy to produce suitable photographic documents (Martins Gomes et al., 1999). Totally, the instruments utilized in the documentation project were as following:

$\begin{array}{ll}\checkmark & \text { A digital camera: Canon Power Shot G11 } \\ \checkmark & \text { A laser distance meter } \\ \checkmark & \text { A GPS } \\ \checkmark & \text { PhotoModeler } 6 \\ \checkmark & \text { AutoCAD 2010 } \\ \checkmark & \text { Google sketchup } 8\end{array}$




\section{DOCUMENTATION PROCESS}

The documentation process of Kharraqan Tower can be summarized according to following the steps:

$$
\begin{array}{cc}
\checkmark & \text { Photography planning \& network designing } \\
\checkmark & \text { Field work /Taking images } \\
\checkmark & \text { Camera calibration } \\
\checkmark & \text { Importing the data into PhotoModeler/ } \\
\checkmark & \text { Processing the images } \\
\checkmark & \text { 3D modeling } \\
\checkmark & \text { Exporting the 3D model into dxf. format } \\
\checkmark & \text { Final processing of 3D model in AutoCAD and } \\
& \text { Sketchup and providing the drawings }
\end{array}
$$

\subsection{Field Work}

As it is obvious, photogrammetry is based on several images (at least two images) with known focal length taken from different angles which overlap each other at least $60 \%$. Accordingly, it is crucial to plan photography and denote the camera stations to make sure about complete coverage of the object. Besides, this planning increases the accuracy, so that better results could be achieved. In this matter, " $3 \times 3$ " rules demonstrated by Waldhäusl and Ogleby (1994) for architectural photogrammetry was considered to better organizing the field work and actually the photography process.

Therefore, the decision was made to take at least three photos of each side of the octagonal object from three different angles. Since the closer to $90^{\circ}$ are the photography angles; the higher accuracy the photogrammetry network can reach; it was determined to take a photo perpendicular to each side, and the other two photos diagonally, so that they make $90^{\circ}$ angle in between.

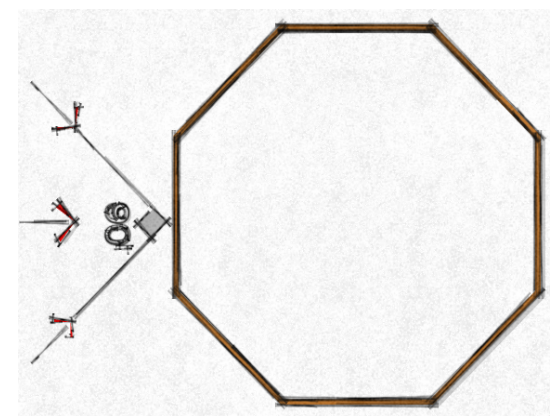

Figure 4. Illustration of camera angles in taking images of each side of the object

In addition, with respect to the " $3 \times 3$ " rules, following points were appreciated during the photography:

All the images were taken convergently with enough coverage, so that a ring of images was created around the building.

$\checkmark \quad$ While photographing, avoided to use the zooming tool of the camera to prevent changing in the focal length, therefore losing the constant geometry of the camera.

$\checkmark \quad$ Details were covered by multiple images.

Finally it was tried to avoid changing in distances between different camera stations and the object.

After finishing the photography, it was necessary to measure distance between at least 2 points of the building to avoid any doubt about the scale of the final model. In addition, to achieve the global position and coordination of the building a GPS was used.

It is necessary to mention that the whole process of field work lasted for two days, one day for surveying and one day -after processing images in PhotoModeler- for checking and examining the accuracy of the final model.

\subsection{Camera Calibration}

A crucial issue which should be considered in photogrammetry to obtain accurate results is camera calibration. Accordingly, because of using a non-metric camera, it was very important to perform calibration process. Thanks to the PhotoModeler program, the calibration process is simplified and can be done easily even by a non-expert user.

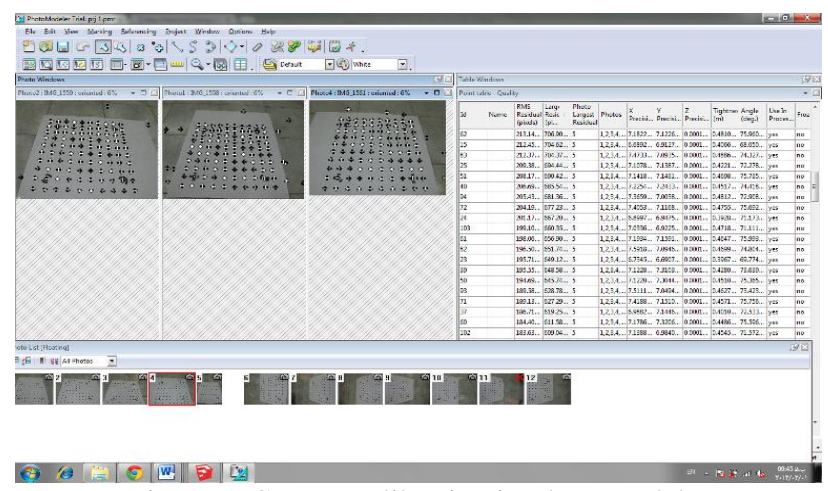

Figure 5. Camera calibration in PhotoModeler

\subsection{Importing the Data into the Software}

While finishing the field work, office work, analysing and processing gathered information should be performed. First, a photogrammetry archive was created using taken images of the tower. Then images were imported into the PhotoModeler software regarding the camera calibration project for post processing and generating the 3D model of the object.

By the use of "point" tool of the software, considered points needed in 3D model were detected, and matching process in different images was done. Then, with the help of "line" and "surface" tools, wireframe and then surface models of the object were generated.

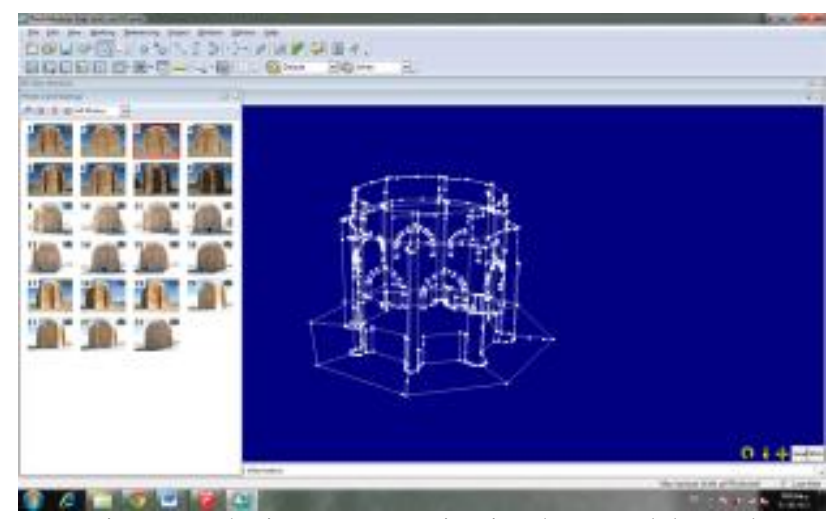

Figure 6. The image processing in PhotoModeler and generating the wireframe model of the object 


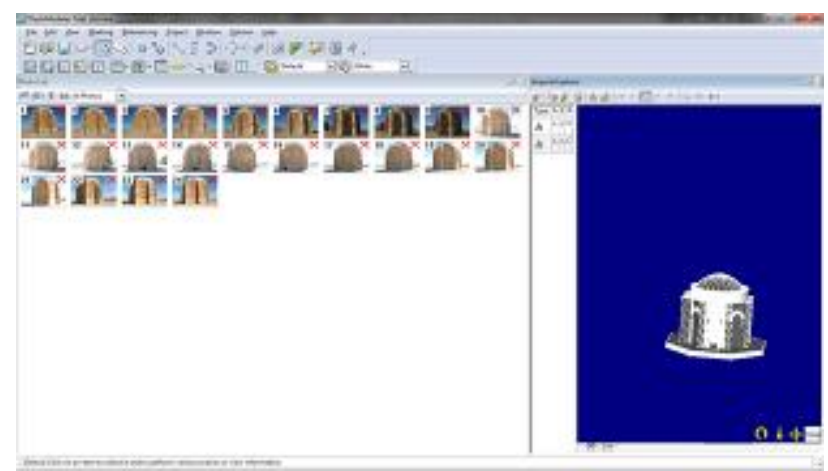

Figure 7. Surface model of the object

Finally, the model was scaled using the measures obtained by hand measuring during field work. The final result was saved as a dxf. format for making the required edits and further analysis with the help of conventional softwares such as AutoCAD.

\subsection{Results and Discussion}

As it was noticed in previous section, the 3D model saved as dxf. format. This file was exported into AutoCAD and Google Sketchup softwares. Using this file it was possible to create plan, elevations, and sections of the building easily. The whole process of importing data and modelling the building took about 15 days while drawing the plans and other documents took one day to be performed.

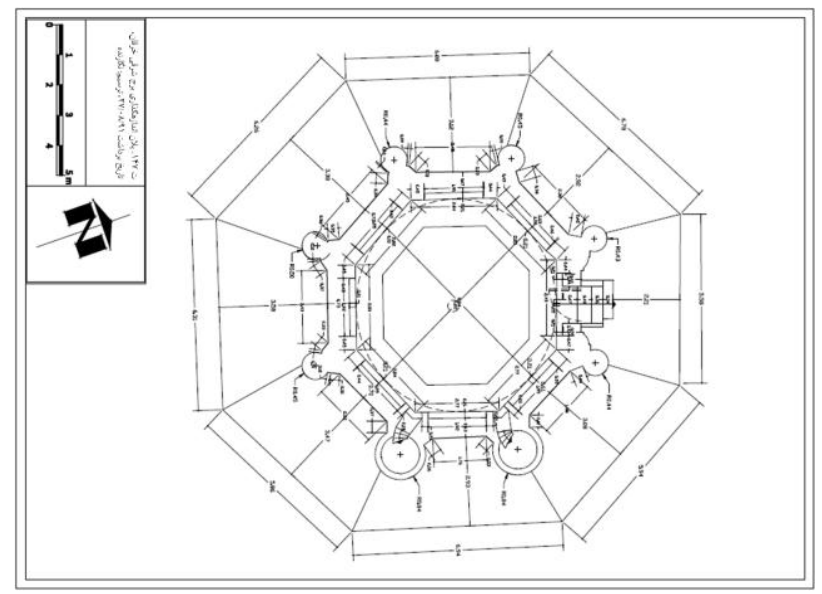

Figure 8. Kharrqan tower plan

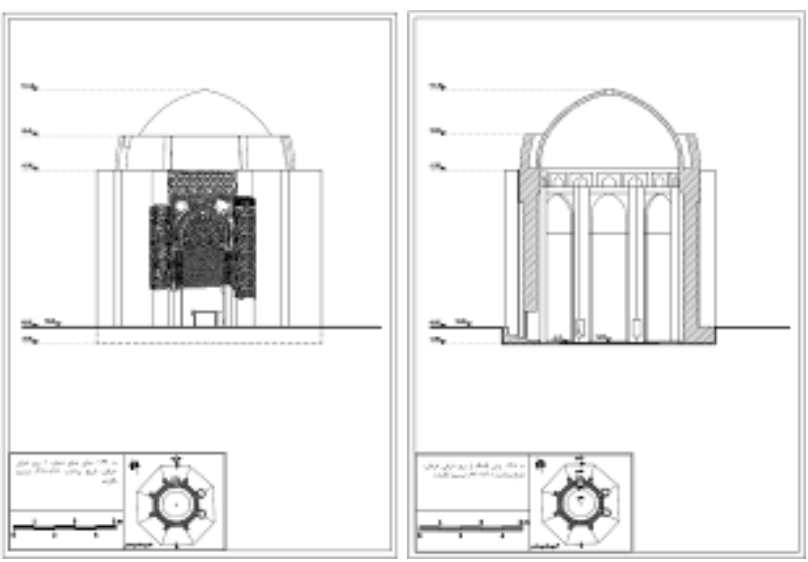

Figure 9. Left: Elevation of first side of the tower, Right: A section of the tower
During performing project some important problems were considered. The most important one was the texturing of the model. Round pillars, curved surfaces and domed cover made the texturing process of the model frustrating. Furthermore, because of changing in light condition during the photography, and the heterogeneous illumination (due to the inappropriate time of photography), the images were not suitable for texturing purpose. This was because of the geometry of the building, so that a part of each side of the tower was in shadow while the other part of that side was simultaneously in sun light. Accordingly, it was not possible to adjust the image light by setting the diaphragm opening of the camera. Thus, with regard to these problems, it was failed to make the texturing process in PhotoModeler and reach photo-realistic texturing model. Accordingly, the final model was textured with the help of Google Sketchup brick patterns, and put into the Google-earth in its real location.
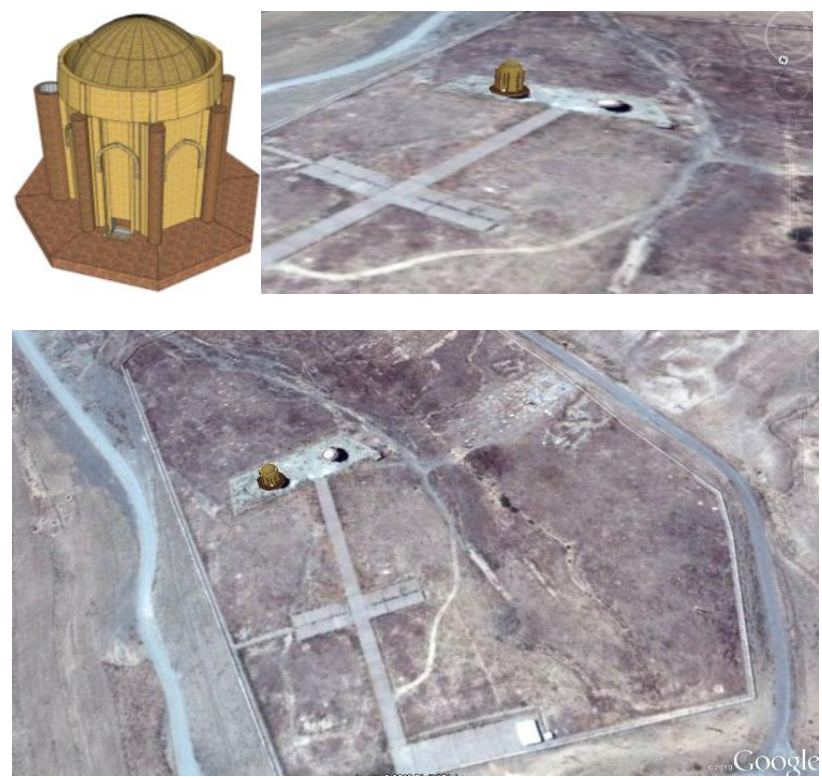

Figure 10. Different views of the 3D model of the tower in Google-earth map

The brick decoration of building was drawn in AutoCAD by the use of rectified partial images taken from different parts.

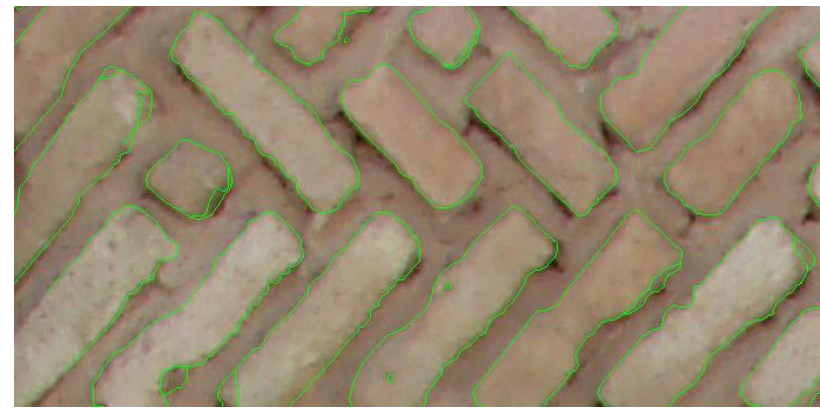

Figure 11. A part of the Brick work decoration of façade, CAD drawing

The process of drawing the brickwork decoration of tower took 4 days for each side of the octagonal shape of the tower. However, because of lack of time and budget this process was done only for two sides of the building. 


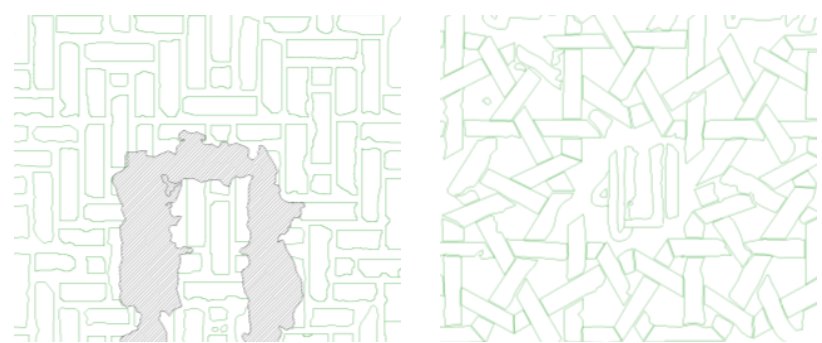

Figure 12. Different Samples of external brick decoration of the tower, CAD drawings

\subsection{Quality Assessment}

Different factors such as the camera resolution, selecting matched points in different images during the modelling process and also light condition while doing field work are very important to achieve proper accuracy.

The overall quality of the project can be discussed based on PhotoModeler report and comparing the results to the results of another technique applied to the tower. To achieve to this purpose, hand measuring with the help of a laser distance meter was done and 7 different distances was measured very carefully and several times to assure the accuracy of the results. By comparing the results of this technique to the results of the close-range photogrammetry the standard deviation was simply calculable. The table below shows measures obtained from hand measuring and PhotoModeler and final standard deviation.

\begin{tabular}{|c|c|c|}
\hline $\begin{array}{c}\text { PhotoModeler } \\
\text { Meas.(m) }\end{array}$ & Ground Meas.(m) & Differences(m) \\
\hline 7.5 & 7.48 & 0.02 \\
\hline 2.41 & 2.45 & -0.04 \\
\hline 2.36 & 2.39 & -0.03 \\
\hline 2.22 & 2.21 & 0.01 \\
\hline 1.78 & 1.76 & 0.02 \\
\hline 2.05 & 2.08 & -0.03 \\
\hline 2.02 & 2.02 & 0 \\
\hline \multicolumn{2}{|c|}{ Standard deviation $=0.0256$} \\
\hline
\end{tabular}

Table 1. Comparing different results of hand measuring and close-range photogrammetry, Calculation of standard deviation

As it can be seen in the table, the amount of standard deviation is $0.0256(\mathrm{~m})$, and it is acceptable for such a project. If calculating approximate, each three pixels of an image is equal to 1 centimeter of the real object. However, according to PhotoModeler report, the overall RMS is 1.142 pixels, which is equal to 0.3 centimeters.

In accord with what it was mentioned about light condition in previous section, and by comparing the calculated standard deviation to PhotoModeler report, it can be concluded that the light condition was very operative in the final result, so that it has caused problems in detecting matched points and reducing the final accuracy of the project.

\section{CONCLUSION}

This project was a part of an experience of documentation research in Iran. Since the most important factor in selecting a proper documentation technique for each project is the available budget, it was intended to examine a cost-effective method to handle the documentation of numerous valuable monuments in Iran. In this project, by exploiting close range photogrammetry using an amateur digital camera, and PhotoModeler program, the 3D model of the eastern Kharraqan Tomb Tower was created by the least possible amount of budget and field work. With the help of $3 \mathrm{D}$ model, it was possible to extract real dimensions and measures of the building, and to provide the drawings and documents of the existing condition of the object. In addition, a photogrammetry archive was provided to be used in case of future needs.

Final result shows that using digital cameras is the best possible answer for documentation of cultural heritage, while facing limited budget. In fact, the use of amateur cameras seems to be the only realistic possibility for a more or less complete and permanently updated documentation of the enormous quantity of architectural and other cultural objects within a reasonably short time (Shashi \& Jain, 2007).

Considering the high speed of destruction because of different factors such as natural disasters, planning for swift documentation is in priority. In this regard, the least possible measure is to create photogrammetry archives using oriented images taken by calibrated cameras.

\section{REFERENCES}

\section{References from Books:}

Atkinson K. B. (Editor), 1996. Close range Photogrammetry and Machine Vision, Whittles Publishing, Latheronwheel.

Karara H.M. (Editor), 1989. Non-Topographic Photogrammetry Second Edition. American Society and Remote Sensing, Science and Engineering Series, Virginia, USA.

Ogleby C.L and L.J. Rivett, 1985. Handbook of heritage photogrammetry. Australian Government Publishing Service, Canberra. 115 pages.

Waldhäusl P. and C. Ogleby, 1994. 3 x 3 Rules for Simple Photogrammetric Documentation of Architecture. J.G.Fryer (Editor), International Archives of Photogrammetry and Remote Sensing, Vol. XXX, Part5, pp. 426 - 429.

\section{References from websites:}

Armesto J., P. Arias, J. Roca and H. Lorenzo, 2008. Monitoring and Assessing Structural Damage in Historic Buildings. The Photogrammetric Record, V. 23, Issues121, pp. 36-50, http://webs.uvigo.es/grupotf1/research/armesto_et_al_PhR.pdf.

Briseghella L. and M. Kalhor, 2007. The Seismic Rehabilitation of Kharraqan Tomb Towers. The $5^{\text {th }}$ international conference on seismology and earthquake engineering, Tehran, Iran http://www.civilica.com/EnPaper--SEE05_386.html.

Droj G., 2010. Cultural Heritage Conservation by GIS, NyugatMagyarországi Egyetem, Geoinformatikai Kar, Székesfehérvár, www.geo.info.hu/gisopen/gisopen2010/eloadasok/pdf/droj.pdf.

Hanke K. and P. Grussenmeyer, 2002. Architectural Photogrammetry: Basic Theory, Procedures, Tools. ISPRS Commission 5 tutorial, International Archives of Photogrammetry and Remote Sensing, http://www.isprs.org/commission5/tutorial02/gruss/tut_gruss.pd f.

Martins Gomes C. J., W. d. S. Prado, H. Erwes and G. D. Koatz, 1999. A Photogrammetric Project in Brazil: the Use of 
the PhotoModeler Software. 17th CIPA Symposium, Olinda, Brazil,

http://cipa.icomos.org/fileadmin/template/doc/olinda/99c313.pd f.

Mills J., G. Peirson, I. Newton and P. Bryan, 2000. Photogrammetric investigation into the suitability of desktop image measurement software for architectural recording, International Archives of Photogrammetry and Remote Sensing, 33 (B5/2), pp.525-532. http://www.isprs.org/proceedings/xxxiii/congress/part5/525_X XXIII-part5.pdf.

Patias P., 2006. Cultural Heritage Documentation, The Aristotle University Faculty of Surveying Engineering, Commission VI Special Interest Group "Technology Transfer Caravan", International Summer School "Digital Recording and 3D Modeling", Aghios Nikolaos, Crete, Greece.

Patias P. and J. Peipe, 2000. Photogrammetry and CAD/CAM in Culture and Industry - An ever changing paradigm, Proc. and CD of ISPRS XIX Congress, Amsterdam, July 16-23. http://www.isprs.org/proceedings/xxxiii/congress/part5/599_X XXIII-part5.pdf.

Patias P., 2001. Caring for the Past, Aiming at the Future: Plans and Policy of ISPRS Commission V. Keynote Address, International Workshop on Recreating the Past -Visualization and Animation of Cultural Heritage, (Ayutthaya, Thailand, 26 Feb. - 1 Mar.), International Archives Photogrammetry and Remote Sensing, 34(5C15): 1-4. http://www.isprs.org/proceedings/XXXV/congress/comm5/pape rs/665.pdf.

Patias P., Stylianidis, E. and Terzitanos, K., 1998. Comparison of simple off-the-self and of-wide-use 3D modelling software to strict photogrammetric procedures for close-range applications. International Archives of Photogrammetry and Remote Sensing, 32(5): 628-632. http://getinfo.de/app/Comparison-of-SimpleOff-the-Self-and-of-Wide-Use/id/BLCP\%3ACN030810913.

Peipe J. and M. Stephani, 2003. Performance evaluation of a 5 Megapixel digital metric camera for use in Architectural Photogrammetry. International Archives of the Photogrammetry, Remote Sensing and Spatial Information Sciences, 34(5/W12): 259-261. http://www.isprs.org/proceedings/xxxiv/5w12/proceedings/65.p df.

Remondino F. and A. Rizzi, 2009. Reality-based 3D Documentation of World Heritage Sites: Methodologies, Problems and Examples. 22nd CIPA Symposium, Kyoto, Japan, http://cipa.icomos.org/fileadmin/template/doc/KYOTO/131-

2.pdf.

Sechidis L., C. Georgiadis, and P. Patias, 1999. Transformations for "Calibrated Image" creation using distortion models Measurements and Processing in Archaeology and Architecture. ISPRS WG V/2 \& WG5 Workshop, Photogrammetric Measurement, Object Modelling and Documentation in Architecture and Industry (Thessaloniki, Greece, 7-9 July), International Archives of Photogrammetry and Remote Sensing, 32(5W11): 215-222.
Shashi M. and K. Jain, 2007. Use of Amateur Cameras in Architectural Photogrammetry. Map World Forum Hyderabad, India,http://www.gisdevelopment.net/proceedings/mapworldfor $\underline{\text { um/poster/mwf_poster_41.pdf. }}$ 